\title{
Erratum to: Comparative analysis of the soil thermal regimes of typical underlying surfaces of oasis systems in an Arid Region
}

\author{
Yinhuan Ao - Shihua Lyu • \\ Bo Han $\cdot$ Zhaoguo Li
}

Published online: 28 February 2015

(C) Springer-Verlag Berlin Heidelberg 2015

\section{Erratum to: Environ Earth Sci}

\section{DOI 10.1007/s12665-014-3937-7}

The authors would like to correct the errors in the original publication as below.

The correct version of the author affiliations is given below:

Y. Ao, S. Lyu, B. Han, Z. Li ( $ه)$

Key Laboratory of Land Surface Process and Climate Change in Cold and Arid Regions, Cold and Arid Regions Environmental and Engineering Research Institute, Chinese Academy of Sciences, Lanzhou 730000, China e-mail: 1zgnuist@163.com

\section{Z. Li}

University of Chinese Academy of Sciences, Beijing 100049, China

The online version of the original article can be found under doi:10.1007/s12665-014-3937-7.

\section{Y. Ao $\cdot$ S. Lyu $\cdot$ B. Han $\cdot$ Z. Li $(\bowtie)$}

Key Laboratory of Land Surface Process and Climate Change

in Cold and Arid Regions, Cold and Arid Regions

Environmental and Engineering Research Institute, Chinese

Academy of Sciences, Lanzhou 730000, China

e-mail: lzgnuist@163.com

Z. Li

University of Chinese Academy of Sciences,

Beijing 100049, China 